\title{
DEVELOPMENT OF A SOFTWARE-BASED MONITORING AND INFORMATION SYSTEM FOR INDUSTRIAL TELEMETRY APPLICATIONS
}

\author{
J. Prinsloo ${ }^{1 * \#}$, M. Mathews ${ }^{1 \dagger}$, J. du Plessis ${ }^{1 \dagger} \&$ J. Vosloo ${ }^{1}$
}

\section{ARTICLE INFO}

\section{Article details}

Submitted by authors 16 Jan 2018 Accepted for publication 13 Mar 2019 Available online 29 May 2019

\section{Contact details}

* Corresponding author jprinsloo@researchtoolbox.com

Author affiliations

1 Centre for Research and Continued Engineering Development, North-West University, Pretoria, South Africa

\# Author was enrolled for his Masters studies at the North-West University's Centre for Research and Continued Engineering Development (CRCED) in Pretoria, South Africa

$\dagger \quad$ Author was a post-doctoral student at the North-West University's Centre for Research and Continued Engineering Development (CRCED) in Pretoria, South Africa

DOI

http: //dx.doi.org/10.7166/30-1-1901

\section{ABSTRACT}

Industry stands to benefit from adopting Internet of Things (IoT) practices. However, reliability and quality of service are of the utmost importance. Challenges such as intermittent connectivity in wide-area wireless communications can hamper the adoption and efficiency of loT principles in industry. The aim of this paper, therefore, is to propose a new system that actively monitors the status of a wide-area wireless communications network to improve quality of service and ensure reliability. The new monitoring system was implemented on a telemetry system that is used by multiple industrial facilities in the Republic of South Africa. Successful monitoring of 80 remote end-points with more than one thousand individual industrial components was achieved, with communication failures or anomalies being detected immediately. In addition to the immediate detection of communication failures, the average connection uplink time was increased by more than 25 per cent.

\section{OPSOMMING}

Die industriële sektor kan baat by die integrasie van 'Internet of Things' (loT) toepassings. Betroubaarheid en gehalte van diens is egter belangrike faktore wat in ag geneem moet word. Huidige uitdagings soos onstabiele konnektiwiteit in koordlose netwerke kan negatiewe gevolge hê in industriële toepassings. Die doel van hierdie studie is om ' $n$ unieke stelsel voor te stel wat in staat is om koordlose kommunikasie netwerke met 'n groot omvang te monitor, met die doel om die gehalte van diens en betroubaarheid van hierdie netwerke te verbeter. Die stelsel was prakties ontwikkel en geïntegreer met 'n bestaande netwerk wat verskeie industriële fasiliteite in die Republiek van Suid-Afrika koordloos verbind. Die stelsel was in staat om tagtig afgeleë industriële eindpunte te monitor. Meer as eenduisend individuele industriële komponente word direk geaffekteer, en konneksie probleme tussen industriële aanlegte was onmiddelik opgespoor. Algehele konnektiwiteit was verbeter met meer as 25 persent.

\section{INTRODUCTION AND BACKGROUND}

The rapid expansion of the Internet into more facets of everyday life paves the way for the establishment of new research and development fields. One such field is the Internet of Things (loT) which, while relatively new, proves set to become a major component of connectivity and communication in the modern era. The term 'Internet of Things' is defined as a paradigm that focuses on the incorporation of existing technologies to achieve interconnected environments, where physical products are connected to the Internet [1]. By extending the Internet and Web into the physical realm, everyday objects can be made 'smart'. With the further interconnection of these various smart objects, new applications can be developed to provide solutions to existing challenges [2]. 
The loT field is experiencing rapid growth in the industrial sector, and the term 'Industrial loT' (IloT) is often referred to as 'the fourth industrial revolution', or 'Industry 4.0' [3]. Industry 4.0 was coined by the World Economic Forum and presented by the German government at the Hannover Trade Fair in 2011 [4]. IoT applications are currently embraced by many industries. Heavy industries, such as mining and steel, have been slower to embrace loT applications. While the use of smart metering and loT has become common place in households and light industry, the power stations generating the power have been less proactive in adopting similar technologies [5].

By extending loT applications into the industrial sector, interconnected systems and processes can be maintained and optimised; this, in turn, may add massive value in production output capabilities by improving efficient production. This is especially important due to the constraints placed on heavy industry by external factors such as government policies, economic volatility, and increased competitiveness [6]. Established heavy industries, such as mining, steel production, water distribution, and power utilities have been slow in adopting loT practices and applications [7]. Much of this hesitance to incorporate loT methods into existing processes is derived from legitimate concerns, such as safety, security, and costs [7].

Most of the heavy industry realm cannot yet be classified as 'smart' industries - they are still operating at a traditional 'best-effort' service level [8]. Heavy industrial facilities are also typically spread over wide geographical areas (such as water pumping schemes) and operate under adverse conditions (such as mines). However, it is still possible to bring this sector into the realm of loT by using existing technologies. With the use of existing technologies such as radio-frequency identification (RFID), wide-area wireless communications such as the global system for mobile communication (GSM) network (including long-term evolution (LTE) networks), and the global positioning system (GPS), it is possible to convert existing industrial processes and operations into 'smart heavy industries'.

System interoperability is considered to be one of the crucial points for any industrial loT ecosystems [9]. The quality of service (QoS) levels of wireless communication systems are considered to be paramount in sustaining the performance and effectiveness of an interoperable system [9]. The reliability and availability of wireless communication services, such as the GSM network, must therefore be ensured in order to allow industrial loT applications to reach their full potential. Gazis [9] highlights various initiatives in the context of machine-to-machine communication that have been introduced to assist in the improvement of wireless quality of service. Most of these initiatives, such as the Internet engineering task force (IETF) and the Telecommunications Industry Association (TIA), focus on maintaining a global standard for communication protocols in order to ensure a global alignment in machine-to-machine (M2M) communication.

Studies have shown that the performance of mobile communication networks can be hampered by current resource-intensive loT applications [10], [11]. Large-scale industrial loT applications might also experience cellular access limitations due to extremely high levels of network traffic. Several models and methods have been proposed to prevent access limitations, such as network access overload control, network access overhead reduction, and network access deadlines [12]. Limitations in wireless networks directly affect the adoption of loT principles in the heavy industry sector [13]. Focus must therefore be placed on guaranteed quality of service in order to allow industry to benefit from loT applications.

By implementing loT solutions in the heavy industry sector, operations can also be made safer and more sustainable [14]. This allows for the development of modular stand-alone systems that can be applied to a wide range of net-centric applications where standards, such as LTE and third or even fourth generation ( $3 \mathrm{G}$ and $4 \mathrm{G}$ ) wireless communications, play a predominant role in wireless data transfer [15].

By extending the loT field into the heavy industry sector, equipment uptime can be increased, maintenance costs can be decreased, and overall equipment and control efficiency can be optimised [16]. By integrating communication between such operations, efficiencies can be achieved by holistically viewing the entirety of operations and processes [17].

It is clear that many industrial loT applications can be considered mission-critical systems. However, challenges currently present in the loT field can hamper the outcomes of 'smart' systems. These 
challenges typically include limited bandwidth, intermittent connectivity of wireless networks, and potential security threats [18].

These challenges have a major effect on quality of service (QoS), which is a critical component in industrial loT applications [19]. Failure to communicate will effectively nullify the advantages of an loT application. The consequences might thus be severe, should the connectivity of an application fail. In the context of industrial IoT applications, communication failure can result in damage to infrastructure and, in extreme cases, lead to loss of life [20]. New methods are therefore required to enhance the QOS of current industrial loT applications and of the underlying fundamentals and building blocks of these applications. The reliability and stability of wide-area wireless communications have been identified as crucial components in the overall effectiveness of loT applications [13].

Thus, to bring heavy industrial players into the loT domain, it is important to address the QoS issues that currently make loT applications unfeasible for these industries. The communication network and its underlying infrastructure are considered to be the limiting factors for industrial IoT applications. The remoteness and layout of some industrial sites require that wide-area wireless communications be used as the predominant method for data transmission.

Therefore, in this paper, a new system is proposed that actively monitors the network layer vital signs of a wide-area wireless telemetry system, and that can be deployed remotely for industrial loT applications. It is believed that integrating this system with existing industrial loT infrastructure will reduce the risk and effect of the current challenges.

The proposed system consists of a cloud-based software application with the ability to monitor various parameters of deployed routers, such as signal strength, data usage, and connection uplink. A design overview, as well as a detailed system design, will be given. This system allows for the connection of heavy industrial equipment to the Internet, which the proposed system then monitors.

The rest of the paper is organised as follows: Section 2 gives an overview of the current loT architecture with a focus on limitations for industrial applications. Section 3 presents a design overview and the methodology of the proposed system. Section 4 provides system results after conducting a case study, and presents a critical analysis of the given results. The potential opportunity for future work is then discussed in Section 5, with Section 6 concluding this paper.

\section{IOT: ARCHITECTURE, METHODS, AND APPLICATIONS}

A clear understanding of the IoT realm (which includes current architecture models, methods, applications, and challenges) must first be obtained from the literature before a solution can be proposed. This section thus presents existing peer-reviewed articles on the architectural structure of the IoT realm. Existing mission-critical systems from peer-reviewed investigations are then presented, and key areas that highlight the contributions of this paper are identified.

\subsection{The loT architecture for industrial systems}

The loT field is broad, and various definitions and architecture models exist [21], [22]. Current architectural models allow for the development of a wide range of loT applications, ranging from smart systems in the private sector to remote monitoring, maintenance, and data acquisition systems in industrial applications [23], [24]. For this study, a generalised architecture model was chosen and adapted to heavy industry, as can be seen in Figure 1. A similar architecture model is presented in a study by Luong et al. [25]; however, the focus of this model is only on the broad loT scope.

Four distinct tasks are present in mission-critical industrial loT applications: the acquisition of data, the transmission of data, the storage and processing of data, and the accessing of data by end-users. A top-down approach is also followed, with the physical layer being the highest tier and the application layer being the lowest tier. A detailed description of each layer is given below:

- Physical layer: The physical layer contains all physical devices that are responsible for data measurement, sensing, and transmission. These devices have limited resources, and are typically used for the acquisition of raw data. Apart from measurement and sensing capabilities, devices in the physical layer can also transmit measurements via the Internet to data storage 
schemes [26]. An example includes pumps and compressors that are controlled by control systems that make use of temperature and flow measurements for effective control [27].

- Network layer: The network layer facilitates all communication within an industrial loT application. For data to be stored and processed remotely, a communication medium is required. The rapid development of communication protocols and methods in the information and communications technology field allows for various communication methods to be used within loT applications [13]. The mobile communication infrastructure is typically used to communicate over large distances. The remoteness of industrial sites can, however, hamper the effectiveness of mobile communications.

- Data layer: Raw data from the physical layer must be processed and stored. The data layer serves as a platform for real-time data processing and storage with the use of cloud-based solutions. By using 'big data' storage mechanisms, large data sets can be stored. This is required, since real-time monitoring of industrial equipment typically results in large data sets on a daily basis. The retrieval and processing of data can also be done with minimal effort [28].

- Application layer: The application layer gives end-users the ability to access data contained in the data layer. The application layer can include application software that resides either with the end-users or in the cloud. The application layer aims to provide users with detailed information that is constructed in a user-friendly manner [25].

Figure 1 below represents a visual map of the key loT concepts discussed above. Key challenges or concerns that can hamper the QoS of industrial systems are identified in each layer.

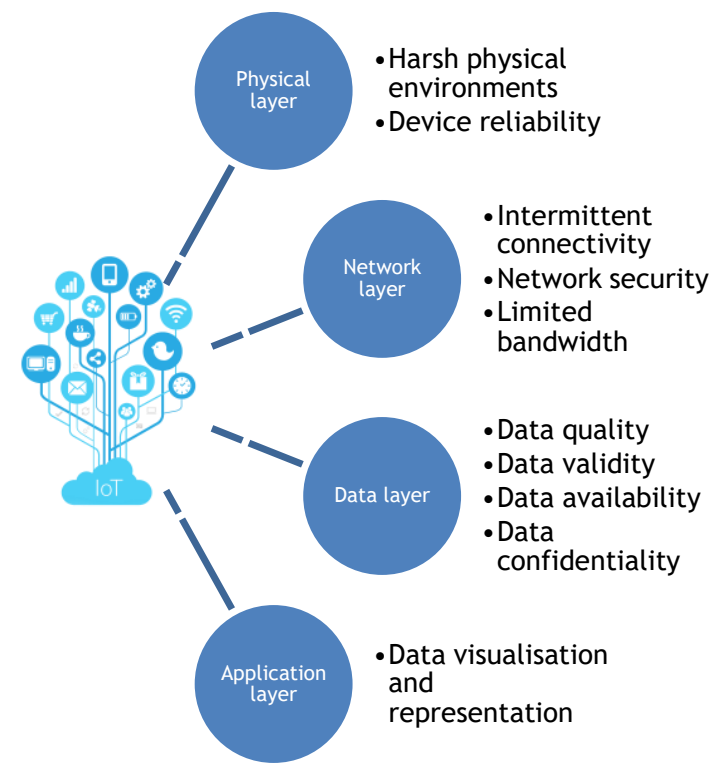

Figure 1: Existing challenges in industrial loT applications

Key challenges within the broader IoT scope focus mainly on the areas of privacy, identity management, and security [29]. Due to the large extent of interconnected devices, standardisation and system interoperability are also flagged as major challenges. With the interconnection of devices and the integration of components on a system level, data storage and data representation become critical parts of ensuring QoS. Finally, the network layer is considered to be the most important layer for industrial loT applications; this layer must therefore be maintained and managed to ensure optimal QoS.

\subsection{Review of existing loT applications and limitations}

Advances in the loT field pave the way for the application of its techniques to industrial loT applications. Systems that ensure and maintain the operational status of critical facilities, such as major water resource pumping schemes or power stations, are examples of important industrial loT applications. These systems can include real-time energy management systems for industrial equipment and remote monitoring and maintenance systems [27], [30], [31]. 
The low-power wireless personal area network with IPv6 (6LoWPAN) is a common communication protocol that is used by sensor networks for communication purposes [31]. This, however, limits systems so that they can only be implemented in a local environment. The communication network is the backbone of the system since, if the network fails, real-time data from the physical layer will not be available. Many loT applications can be made inefficient if data transfer is poor due to poor network reliability or network failure. For example, failure of a Wi-Fi or cellular network used in a preventative medical care telemetry system could have consequences for patient care [32].

Several network monitoring systems have been proposed in the literature. Civerchia, Bocchino, Salvadori, Rossi, Maggiani and Petracca [33] proposed a localised industrial Internet of Things monitoring system for predictive maintenance applications. The main objective of the system is to facilitate continuous monitoring of industrial machinery. This allows for the implementation of predictive maintenance applications and strategies.

Although this system successfully achieved real-time monitoring of industrial equipment, it should be noted that emphasis was placed on the monitoring of industrial equipment, and not on the communication network that facilitates data transfer. Secondly, the system was implemented in a localised environment where sensor nodes could be easily installed and monitored. When industrial plants are separated by wide geographical distances, the quality and reliability of wide-area wireless telemetry becomes a concern, and this system does not address the challenges present in wide-area wireless communication [34].

Gisbert, Palau, Uriarte, Prieto, Palazón, Esteve, López, Correas, Lucas-Estan, Giménez, Moyano, Collantes, Gozálvez, Molina, Lázaro, and González [35] proposed a system that can monitor the performance of heterogeneous wireless networks in the context of local 'smart' factories. One key feature of the proposed system is the ability to reconfigure wireless communication nodes based on the quality of the network. The aim of the system is to help guarantee the robustness and reliability of wireless communications in the context of smart factories. The quality and reliability of widearea wireless communication networks is, however, not addressed.

The stability of the communication network is a deciding factor for all the systems' QoS. This is specifically important for industrial loT applications that are very sensitive to any disruption in production or reduction in safety. Wide-area wireless communications are, however, typically used as the backbone of the communication network for applications that retrieve data from remote endpoints [13].

Reliable and dependable loT solutions are considered to be of the utmost importance; network layer reliability, stability, privacy, and security are essential [36]. The system proposed in this paper serves as a solution to the challenge mentioned above. There is thus a need to develop and integrate a system to maintain QOS specifically for heavy industrial loT applications where a lack of communication is not acceptable and the vagaries of the industry make communication more complex.

\section{SYSTEM OVERVIEW AND IMPLEMENTATION}

A monitoring system is proposed that can monitor the communication system to detect changes in the quality of the communication uplink between the physical layer and the data layer. The objective of the proposed solution is to detect faults in the network layer of complex industrial loT applications.

By implementing a remote server and mobile communication router at an industrial facility, the facility can be connected to the web, which would allow for the implementation of loT applications such as remote monitoring and maintenance. Figure 2 shows a conceptual layout of remote facilities that are connected via an existing mobile communications network.

This connection is facilitated by mobile communication routers, and it allows for critical data to be transferred wirelessly over large distances. However, the system makes use of third-party mobile communications networks over which the facility has no control. 
There is thus a need to monitor the QoS of the network independently from the facilities side, to ensure optimum operation of their loT applications. The proposed monitoring system focuses on monitoring the status of the wireless connection uplink.

In the sections that follow, a brief system overview is given, as well as a detailed design description of the proposed solution.

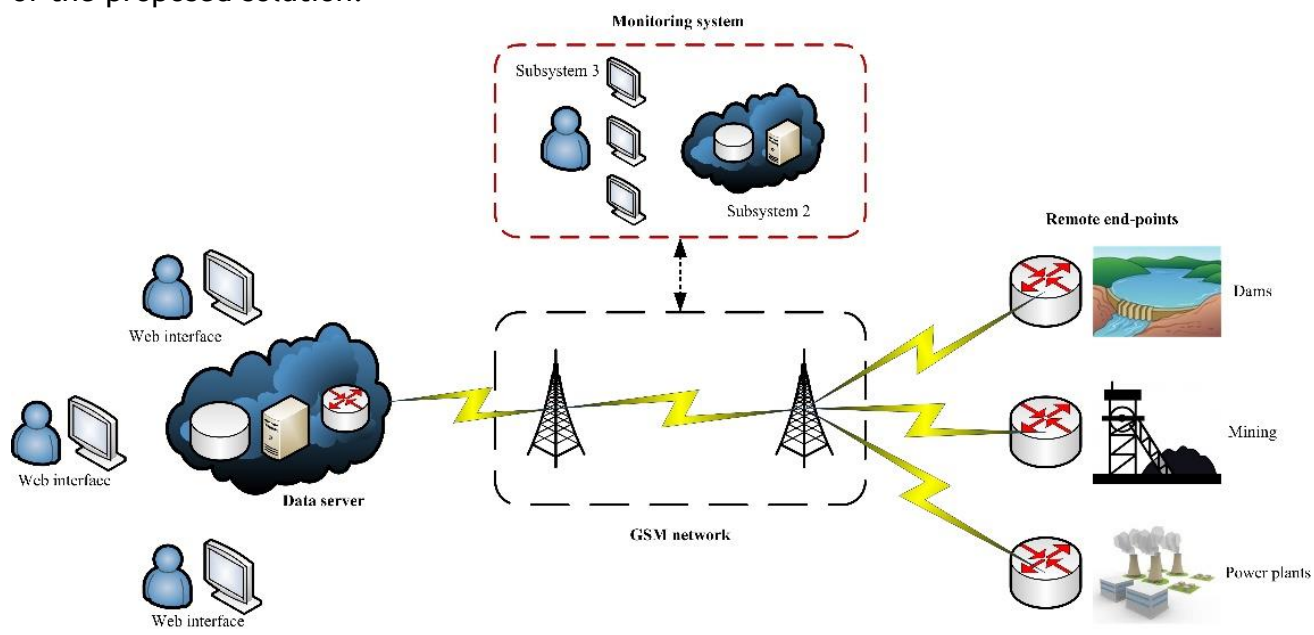

Figure 2: A conceptual diagram of a typical industrial loT application

\subsection{System overview}

The proposed monitoring system can be divided into three subsystems. Figure 3 below illustrates these different subsystems, as well as the underlying structure of each subsystem.

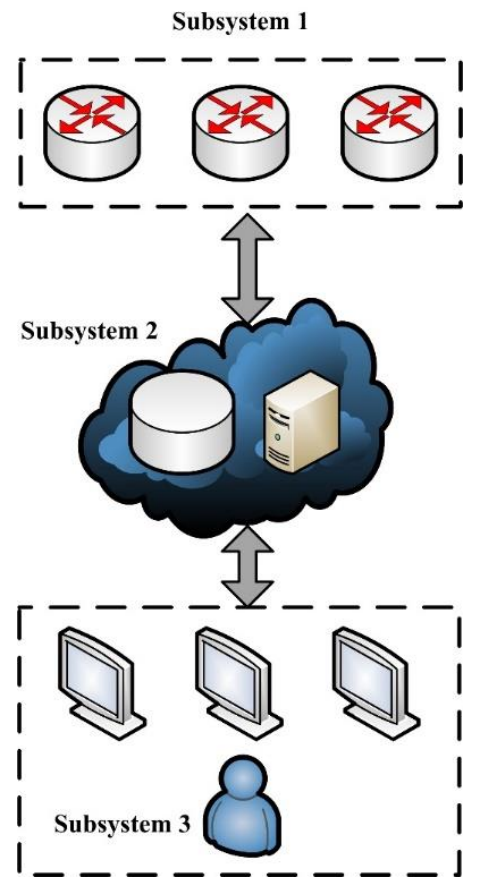

Figure 3: A basic overview of the three main subsystems

Subsystem 1 is considered to be the most important component of the system. This system consists of software routines that actively monitor the vital parameters of the network equipment, and specifically the GSM routers that are used for machine-to-machine communication. The vital parameters include the communication uplink status and the amount of mobile data currently 
available. Signal strength is also considered to be a vital parameter, and is therefore included in the subsystem.

Subsystem 2 focuses on the storage of the information retrieved in subsystem 1. A relational database has been designed and implemented to facilitate the storage. The monitoring system can also retrieve information on a real-time basis, and real-time storage schemes have thus been incorporated into the design. Daily averages are, however, also calculated by subsystem 2, which implies that daily average storage schemes are also required. This has therefore been incorporated into the design.

Subsystem 3 consists of the graphical user interface (GUI), as well as event logging capabilities. For the proposed monitoring, all information is displayed in real-time. A GUI has thus been designed to relay all data to the appropriate end-user stations. From these stations, it is possible to view realtime updates on the connection uplink, the current mobile data usage profile, and the signal strength. Additional information can also be viewed, such as the IP address of the remote end-point.

Most industrial loT applications make use of M2M protocols to facilitate data transfer between offices and remote sites. In order to establish a secure connection between the remote end-point and the receiving end-point, a private access point name (APN) or virtual private network (VPN) is used. With the use of an APN, each remote end-point is provisioned with a unique internet protocol (IP) address [37]. The only way to enable this communication effectively is by using mobile routers.

Thus the proposed system is designed to monitor the communication between a mobile communication router and an existing cloud infrastructure. The proposed system is responsible for monitoring the uplink between remote industrial sites and the receiving end-point to which data is transmitted.

\subsection{Monitoring method}

Two techniques were identified for monitoring a network: active and passive [38]. An active measurement approach has been followed for the proposed monitoring system. Active probing is used by transmitting internet control message protocol (ICMP) packets across the network to the remote end-point.

Generally, due to security concerns, most routers filter out ICMP packets. However, since all remote end-points are registered on a private APN, it is still possible to use ICMP packets to determine whether the remote end-point has a stable connection. The monitoring system can be configured to have one of three restriction profiles: server, administrator, or viewer. The server profile gives the system full access to executing active probing procedures. One restriction on the use of the server profile is that the system must have access to the APN.

The administrator profile allows for the addition or removal of remote end-points, but the application does not have the right to execute active probing procedures. The viewer restriction profile only allows for the viewing of the current network status. Active probing methods cannot be executed when the application is in viewing mode. The monitoring system has been designed with a modular approach in mind. It is therefore easy to add additional end-points for monitoring purposes. In order to optimise the performance of the monitoring system, multithreading techniques have been employed for all software routines.

All active probing routines, as well as database operations, are thus executed in a multithreading environment. This allows for effective monitoring of remote end-points, regardless of the number of end-points that need to be monitored. Figure 4 below illustrates the main software flow of the monitoring system. The software routine is executed periodically in a real-time fashion. Since data is transmitted from each site on a daily basis, the frequency of execution can be narrowed to hourly intervals. This interval was chosen so as not to flood the network with ICMP packages. The interval can, however, be adjusted if required.

Real-time monitoring can only be achieved if a connection to the relational database is available. A database connection check is therefore first executed. In the absence of a database connection, the monitoring routine should not be executed and no data displayed to the user. If a successful database connection is active, the status of the host machine determines whether the monitoring routine can be executed. 
If the host machine is idle, all remote IP addresses are retrieved from the database and stored in a data structure. Worker threads are then created, with each worker thread responsible for checking the connection status of a single IP address. By using active probing, all active remote end-points will reply. The resulting replies are then stored in the database for processing and display purposes.

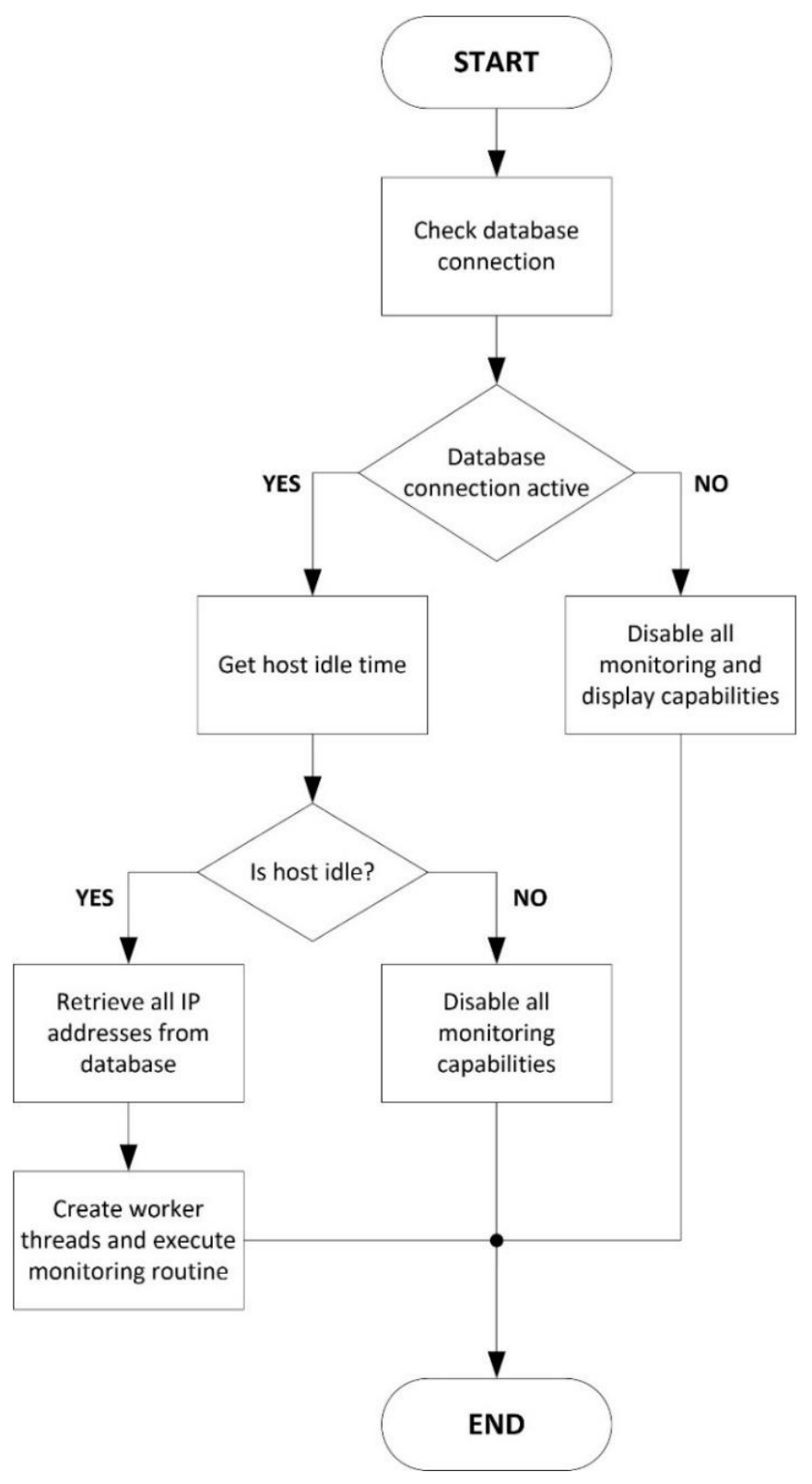

Figure 4: The main software flow of the monitoring system

\subsection{Database design}

A relational database schema has been designed and two tables created to facilitate real-time data storage. The first table facilitates real-time storage of all active probing results, while the second table stores a daily average value that has been calculated by the monitoring system. Figure 5 below shows the details of the two schemas. 


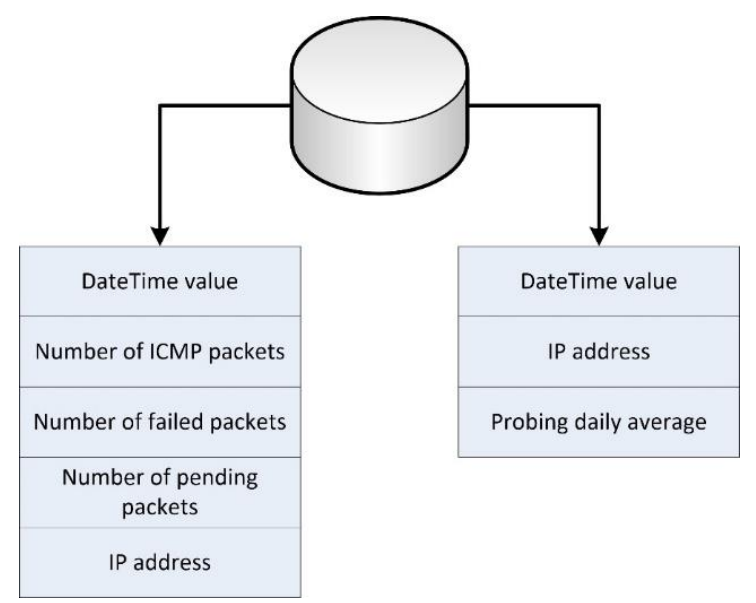

Figure 5: Relational database schemas

Since the proposed system monitors and stores results in real time, data aggregation is considered to be a key component of the database design. Data aggregation assists with reducing the size of the database as well as the query execution time, which results in an overall improvement of system performance.

\subsection{Graphical user interface}

To visually display real-time information, a graphical user interface is required. Since more than one network should be monitored, a grid is compiled, with each entry in the grid containing information relating to a specific end-point. In addition to the status of the network, other information - such as the device signal strength and the current data use - is also displayed.

Site-specific data is also displayed, such as the site IP address, the port number that is required for remote access, and the person responsible for the site. This site-specific information is relevant, as it is required in order to improve proactive maintenance procedures.

The current GUI has been designed to allow for the display of the system in a control room setup, but it could be modified to accommodate other monitoring configurations. A control room typically consists of multiple monitors from which personnel can perform their duties. The control room is thus the ideal place to run multiple client versions of the system, since multiple service personnel use the control room. From the control room, personnel will be able to obtain access to their specific remote sites, and will be able to monitor the real-time status of their sites at any given moment. The implementation architecture of the system can be viewed in Figure 6. Client versions of the system must be distributed on multiple workstations.

The implementation architecture of the system has therefore been designed to include one server application that runs on a dedicated server. The main objective of the server application is to facilitate real-time monitoring of the communication uplink and the storage of the data in the relational database, as discussed in the previous section. The client applications have direct access to the database, as this is required to provide a continuous live feed view of the status of each remote end-point.

Figure 7 below illustrates how the remote end-point data is represented on the graphical user interface. An administrator version of the developed system is shown. All data, as well as historical tracking of connection uplinks, is displayed in order to provide users with the means to make performance-based decisions. 


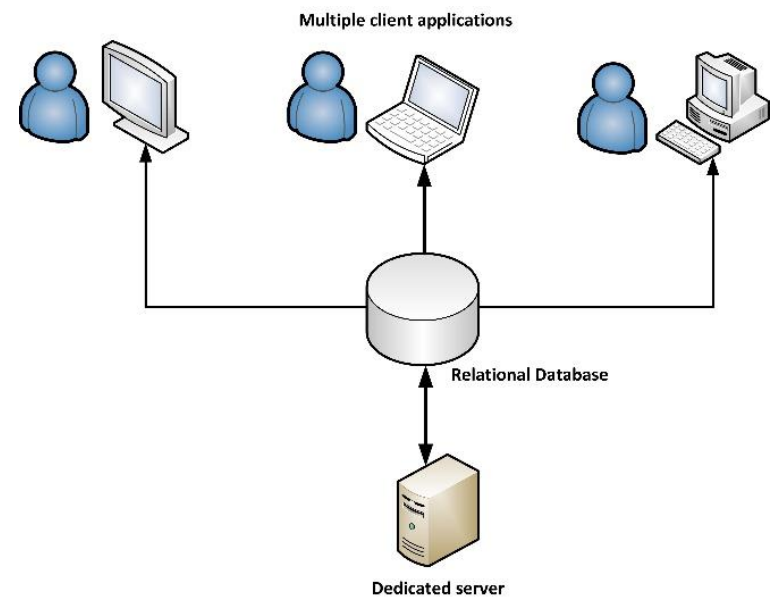

Figure 6: Implementation architecture of the system

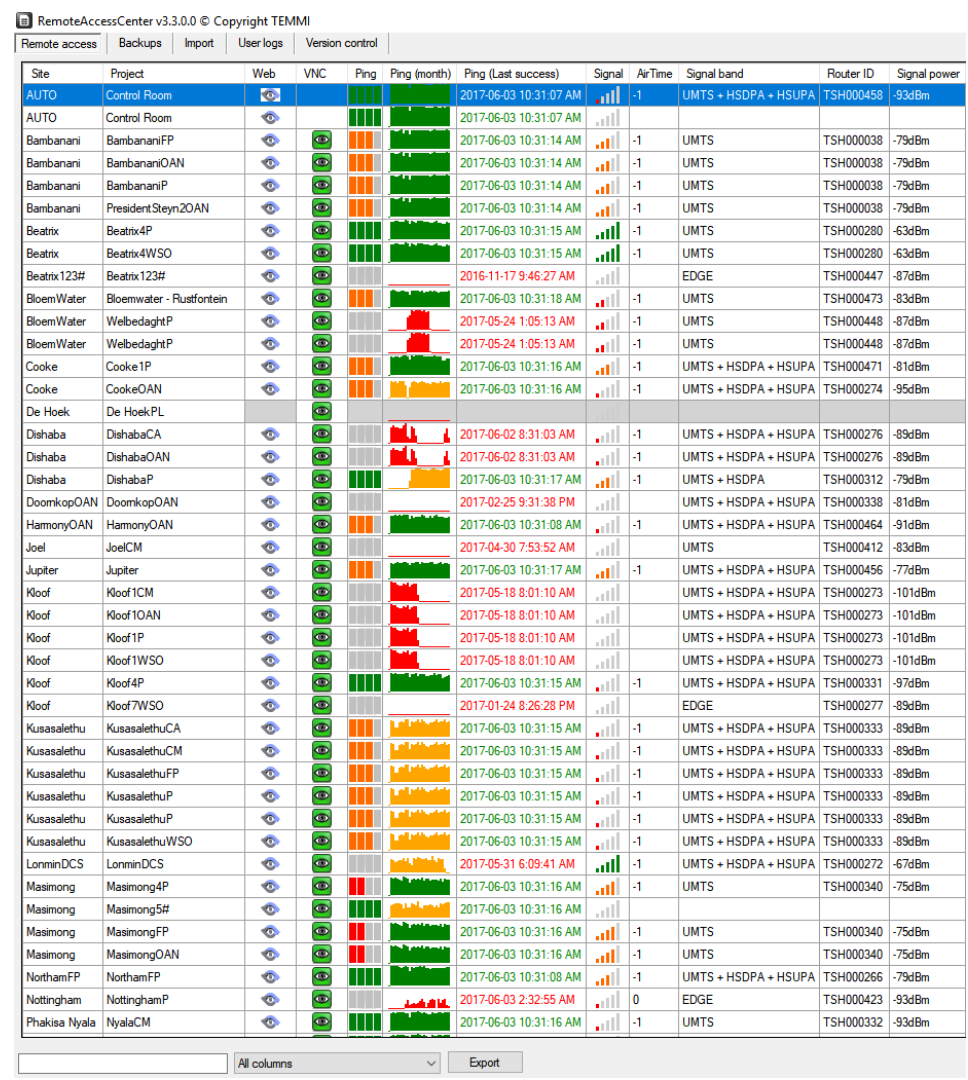

Figure 7: The graphical user interface of the developed monitoring system

\section{RESULTS}

\subsection{Scope}

The proposed system was implemented on an existing machine-to-machine telemetry network. This network was established by an energy services company (ESCo) to implement energy management systems (EMS) effectively for various industrial consumers distributed across the Republic of South Africa. Currently, the ESCo actively maintains energy projects in seven of the nine provinces in the Republic of South Africa, as shown in Figure 9. The receiving end-point for all energy data is, however, located in the Gauteng Province, marked with green in Figure 8. This creates an loT-based EMS. 


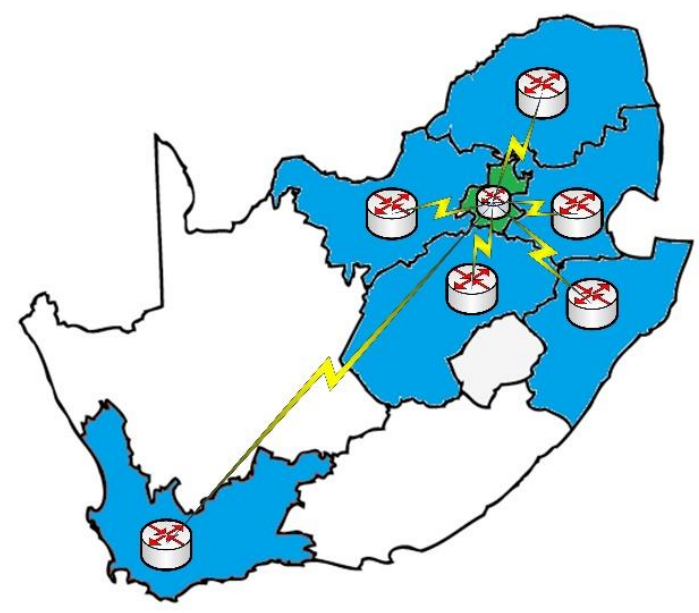

Figure 8: Map showing the geographical reach of the implemented system in the Republic of South Africa (see online version for colour)

Raw data from all remote sites connected to the telemetry network is transmitted daily to a central server. An energy management information system is then used to process the raw data and display all relevant information.

In the industrial sector, EMSs are deployed to reduce the energy consumption profiles of consumers. EMSs also facilitate electricity cost savings for the consumer, and reduce the load on the electricity supplier during peak consumption periods [39]. An EMS can automatically control industrial equipment from predefined control philosophies [27], [40]. In addition to control operations, these systems can also perform data and event logging. Dynamic changes in production profiles also imply that continuous maintenance needs to be performed on the EMS [30].

In order to assist with EMS maintenance, Du Plessis, Pelzer and Vosloo [41] introduced a reactive maintenance approach to sustain, and possibly improve, the performance of existing EMSs. The development of a remote diagnostics and maintenance system allows for a remote EMS to be connected to a maintenance control centre through a secure communication channel [30].

The challenge present in the proposed system is that an unreliable communication link to the remote EMS can result in data loss and poorly maintained energy savings initiatives. This hampers the effectiveness of remote diagnostic and maintenance systems, and causes energy management systems to underperform. Energy management systems are considered to be critical industrial systems because they perform real-time dynamic control on industrial equipment.

Thus the consequences might be severe if control fails on a site and the communication to that site is unstable. Unfortunate consequences not only include the underperformance of EMS systems, but also safety issues and unwanted interruptions in service delivery or production schedules.

Some of the components monitored by the EMS include water pumping schemes in water-scarce regions, and sophisticated control systems on production-sensitive machine components in mines and processing plants. This system can therefore be improved by including a network layer monitoring system, as proposed in this paper, that actively monitors the status of the network to ensure optimum service delivery of the loT-based EMS system.

\subsection{Uplink monitoring}

Figure 9 and Figure 10 are representative of the connection uplink for two independent critical facilities situated at remote locations. Table 1 lists the overall impact of the system. For this study, a total of 80 remote sites were monitored by the system. The remote sites include platinum mines, gold mines, processing plants, coal power plants, and major pumping schemes. The underlying 
industrial equipment used on these sites includes compressors, pumps, fridge plants, fans, actuators, bulk air coolers, and measurement devices.

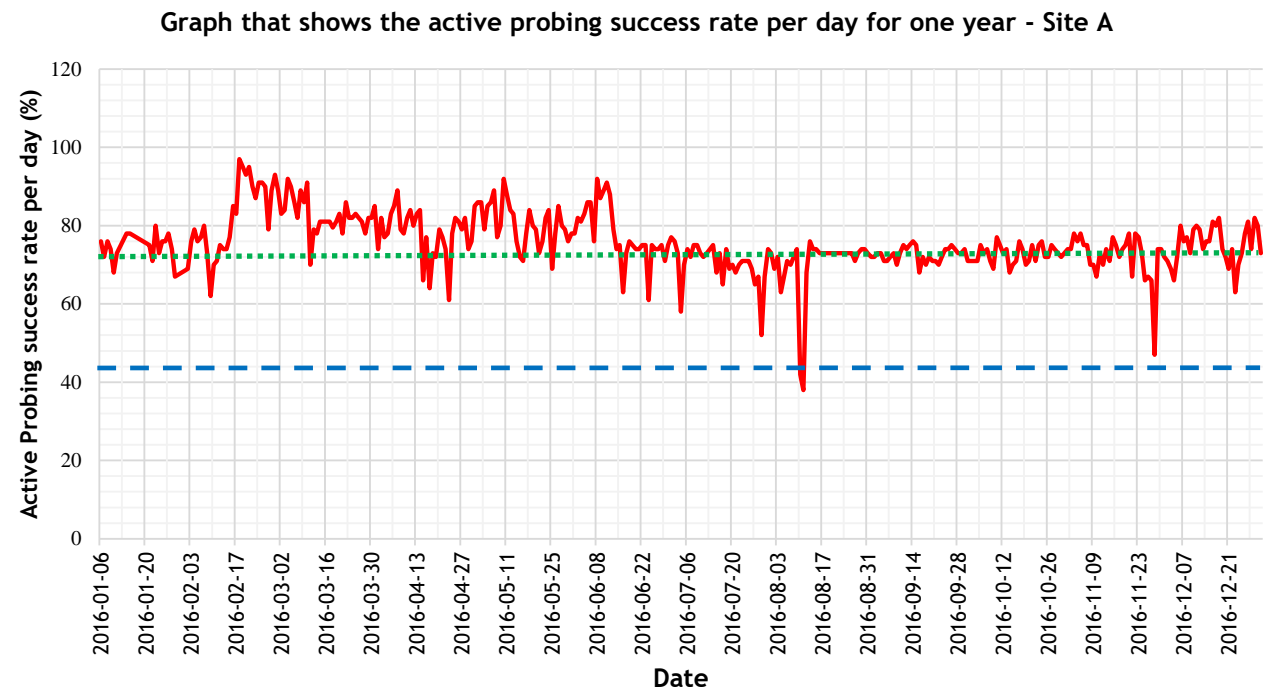

Figure 9: An example of a remote end-point that has a stable connection uplink

Graph that shows the active probing success rate per day for one year - Site B

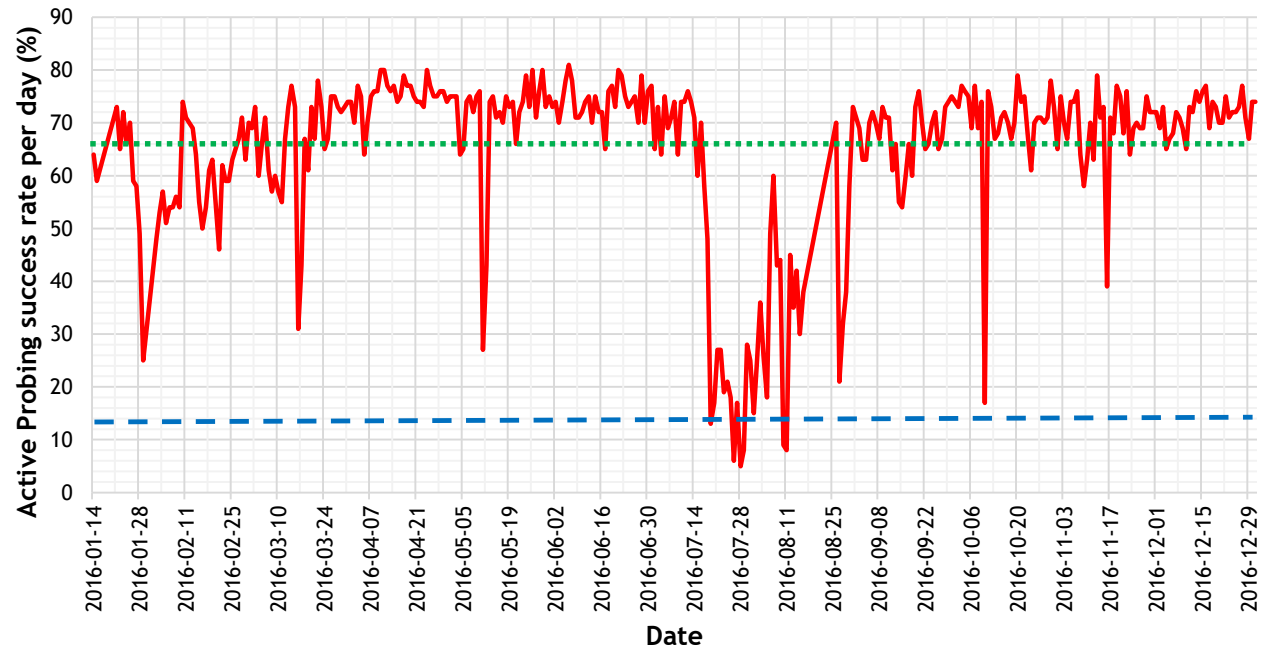

Figure 10: An example of a critical facility that experienced connection issues at some point

Table 1: Monitoring system overview

\begin{tabular}{|l|c|c|}
\hline \multicolumn{1}{|c|}{ Description } & Value & Percentage (\%) \\
\hline Number of sites monitored & 80 & $\mathrm{n} / \mathrm{a}$ \\
\hline Number of healthy sites & 57 & 71.25 \\
\hline Number of unhealthy sites & 11 & 13.75 \\
\hline Number of dormant sites & 12 & 15 \\
\hline
\end{tabular}

With the monitoring of 80 sites, the total amount of heavy industry equipment being monitored is well over a thousand individual components. Monitoring results for the 80 sites were obtained on an hourly basis to ensure that connection issues were identified as fast as possible before the daily transmission of raw data. It was found that active probing on an hourly basis gave an accurate 
account of the uplink status, while keeping the load on the mobile communications router within an acceptable range.

A 24-hour sample size was also found to be large enough to identify all sites that experienced connection issues. Dormant connections were also identified and marked for investigation. Before the implementation of the system, the number of sites with unhealthy connections and of dormant sites were unknown. Personnel were thus tasked to investigate continuously the cause for data loss at the receiving end-point.

Before the implementation of the system, no connection monitoring was done. After system implementation, the first three months were used as the baseline to evaluate the operation of the system. The baselines for all monitored sites have been determined by calculating the average active probing success rate per day for a period of three months. The baselines are indicated by the blue dashed line in Figures 9 and 10.

A clear improvement in network communication can be seen in both sites after three months of operation. The improved baseline after three months of operation is indicated by the green dotted line in Figures 9 and 10. The active probing success rate for site $A$ increased from 42 per cent to about 70 per cent. For site $B$, the active probing success rate increased from 12 per cent to about 65 per cent.

Figure 9 shows the result of a stable communication uplink, with an active probing success rate per day of between 60 and 100 per cent. Figure 10 above shows the result of a critical facility that experienced connection issues in the month of July 2016. The monitoring system allowed for the immediate detection of the state of the network. This prompted investigations to be conducted on the site in order to determine the cause of the unstable connection.

The primary objective of the proposed system was actively to monitor the vital signs of a GSM-based telemetry system. The system thus monitored and displayed the status of a mission-critical telemetry system on a real-time basis. The results of two independent remote end-points using this system found that unstable connections were identified within one hour of operation. This clearly illustrates the benefits of implementing such a system on existing industrial loT applications to ensure optimum service delivery.

Greater benefit from the loT-based EMS in the case study of this paper was achieved due to an increase in the stability of the network layer. This system can also be expanded to incorporate other mission-critical industrial applications, as described in Section 2.

\section{FUTURE WORK}

As with all ongoing research and development, there is room for the improvement and expansion of the current monitoring system. The current version of the system requires a server for effective operation. Two expansion opportunities are thus presented that would extend the operational functionality of the system.

The first expansion opportunity is to incorporate methods that would allow for the automatic generation of reports. Automatic report generation can be included within the system, or the system can be integrated with dedicated report generation systems, such as the system designed by Liebenberg [42]. By generating reports from the data, detailed analyses can be done on the state of the network infrastructure. It is believed that automatic reports could have a positive impact on telemetry QoS.

The second expansion opportunity is to incorporate the system into a web-based information and data consolidation system, such as the system designed by Goosen [43], since a desktop application is considered to have a limited impact. Expanding the monitoring system into a web-based system will thus improve the system's sphere of influence. Security is, however, a concern, and this will need to be addressed by implementing appropriate security measures.

The proposed system can also be implemented in the corporate world for the monitoring of company handheld devices, such as cell phones, tablets, and rugged smart devices. This is regarded as potential future work for the expansion of the system. 
The impact of an unstable communication network in the field of industrial loT applications can be severe. Extensive study of existing mission-critical systems showed that network layer monitoring is seldom incorporated into the designs of industrial loT systems. Therefore, as described in this paper, a novel monitoring system that monitors the communication uplink status of remote wide-area wireless communication end-points was developed. The objective of this study was to develop and integrate this system into existing industrial loT infrastructure in order to improve the robustness of existing infrastructure.

The proposed system has been designed and implemented on existing energy management projects of an established energy services company. A total of 80 remote end-points, encompassing over a thousand individual components, were incorporated into the system for monitoring purposes. Unstable connections were successfully flagged and earmarked for investigation. Necessary steps were then taken to rectify the issues.

The results achieved demonstrate that real-time monitoring of mission-critical end-points was successfully achieved. The integration of this system further improved the robustness of industrial IoT infrastructure. It is believed that the incorporation of the proposed system will serve as motivation to incorporate loT solutions and applications in the heavy industry realm.

\section{ACKNOWLEDGEMENTS}

The authors express their gratitude to ETA Operations for the support provided to test and implement the monitoring system. The authors are also grateful for the engineers of ETA Operations, who provided continuous feedback from the site. The authors also gratefully acknowledge and thank the reviewers for their suggestions, which helped to improve the overall quality of the paper.

\section{REFERENCES}

[1] Prinsloo, J \& Malekian, R. 2016. Accurate Vehicle Location System Using RFID, an Internet of Things Approach. Sensors, 16(6), p. 825.

[2] Gubbi, J., Buyya, R., Marusic, S. \& Palaniswami, M. 2013. Internet of Things (loT): A vision, architectural elements, and future directions. Future Generation Computer Systems, 29(7), pp. 1645-1660.

[3] Rana, A. \& Lehal, G. S. 2015. Smart Computing Prototype for Industry 4.0 Revolution with IOT and Bigdata Implementation Model. Indian Journal of Science and Technology, 8(35), pp. 1-7.

[4] Prinsloo, J., Mathews, M. J., du Plessis, J. N. \& Vosloo, J. C. 2018. An Information Systems Approach to the Proactive Management of Subscriber Identification Modules in Industry. SAIIE29 Proceedings, pp. 127 138.

[5] Shrouf, F., Ordieres, J. \& Miragliotta, G. 2014. Smart factories in Industry 4.0: A review of the concept and of energy management approached in production based on the Internet of Things paradigm. 2014 IEEE International Conference on Industrial Engineering and Engineering Management, pp. 697-701.

[6] Zhao, Y. \& Cui, Y. 2016. Institutional Review of China's M\&A Policy and An Analysis on Its Effectiveness. 2016 International Conference on Logistics, Informatics and Service Sciences (LISS). pp. 1-4.

[7] Zhang, F., Liu, M., Zhou, Z. \& Shen, W. 2016. An loT-Based Online Monitoring System for Continuous Steel Casting. IEEE Internet of Things Journal, 3(6), pp. 1355-1363.

[8] Ning, H. \& Hu, S. 2010. Securing cognitive radio networks. International Journal of Communication Systems, 23(5), pp. 633-652.

[9] Gazis, V. 2017. A Survey of Standards for Machine-to-Machine and the Internet of Things. IEEE Communications Surveys \& Tutorials, 19(1), pp. 482-511.

[10] Nielsen, J. J., Pratas, N. K., \& Popovski, P. 2015. What can wireless cellular technologies do about the upcoming smart metering traffic?. IEEE Communications Magazine, 53(9), pp. 41-47.

[11] Durisi, G., Koch, T., \& Popovski, P. 2016. Toward Massive, Ultrareliable, and Low-Latency Wireless Communication With Short Packets. Proceedings of the IEEE, 104(9), pp. 1711-1726.

[12] Corrales, G., Stefanovic, C. \& Popovski, P. 2014. Reliable Reporting for Massive M2M Communications With Periodic Resource Pooling. IEEE Wireless Communications Letters, 3(4), pp. 429-432.

[13] Dhillon, H. S., Huang, H. \& Viswanathan, H. 2017. Wide-area Wireless Communication Challenges for the Internet of Things. IEEE Communications Magazine, 55(2), pp. 168-174.

[14] Da Xu, L., He, W. \& Li, S. 2014. Internet of Things in Industries: A Survey. IEEE Transactions on Industrial Informatics, 10(4), pp. 2233-2243.

[15] Kamilaris, A. \& Pitsillides, A. 2016. Mobile Phone Computing and the Internet of Things: A Survey. IEEE Internet of Things Journal, 3(6), pp. 885-898.

[16] Page, P. R., Abu-Mahfouz, A. M. \& Yoyo, S. 2016. Real-time Adjustment of Pressure to Demand in Water Distribution Systems: Parameter-less P-controller Algorithm. Procedia Engineering, 154, pp. 391-397. 
[17] Ungurean, I., Gaitan, N. C. \& Gaitan, V. G. 2014. An loT architecture for things from industrial environment. 2014 10th International Conference on Communications (COMM), pp. 1-4.

[18] Sicari, S., Rizzardi, A., Grieco, L. A. \& Coen-Porisini, A. 2015. Security, privacy and trust in Internet of Things: The road ahead. Computer Networks, 76, pp. 146-164.

[19] Zhang, R., Wang, M., Shen, X. \& Xie, L. L. 2016. Probabilistic Analysis on QoS Provisioning for Internet of Things in LTE-A Heterogeneous Networks With Partial Spectrum Usage. IEEE Internet of Things Journal, 3(3), pp. 354-365.

[20] Shi, J. Y. 2015. On the Resilience of Mission Critical Applications. 2015 Resilience Week (RWS), pp. 199201.

[21] Agrawal, S. \& Vieira, D. 2013. A survey on Internet of Things. Journal of King Saud University - Computer and Information Sciences, 1(2), pp. 78-95.

[22] Yue, Z., Sun, W., Li, P., Rehman, M. U. \& Yang, X. 2015. Internet of things: Architecture, technology and key problems in implementation. 2015 8th International Congress on Image and Signal Processing (CISP), pp. 1298-1302.

[23] Zanella, A., Bui, N., Castellani, A., Vangelista, L. \& Zorzi, M. 2014. Internet of Things for Smart Cities. IEEE Internet of Things Journal, 1(1), pp. 22-32.

[24] Miorandi, D., Sicari, S., De Pellegrini, F. \& Chlamtac, I. 2012. Internet of things: Vision, applications and research challenges. Ad Hoc Networks, 10(7), pp. 1497-1516.

[25] Luong, N. C., Hoang, D. T., Wang, P., Niyato, D., Kim, D. I. \& Han, Z. 2016. Data Collection and Wireless Communication in Internet of Things (IOT) Using Economic Analysis and Pricing Models: A Survey. IEEE Communications Surveys \& Tutorials, 18(4), pp. 2546-2590.

[26] Abi, R., Daou, Z., Aad, E., Nakhle, F., Hayek, A. \& Börcsök, J. 2015. Patient Vital Signs Monitoring via Android Application. International Conference on Advances in Biomedical Engineering, pp. 166-169.

[27] van Heerden, S. W., Pelzer, R. \& Marais, J. H. 2014. Developing a dynamic control system for mine compressed air networks. 2014 International Conference on the Eleventh industrial and Commercial Use of Energy, pp. 1-8.

[28] Barnaghi, P. \& Sheth, A. 2016. On Searching the Internet of Things: Requirements and Challenges. IEEE Intelligent Systems, pp. 71-75.

[29] Trappey, A. J. C., Trappey, C. V., Hareesh Govindarajan, U., Chuang, A. C. \& Sun, J. J. 2017. A review of essential standards and patent landscapes for the Internet of Things: A key enabler for Industry 4.0. Advanced Engineering Informatics, 33, pp. 208-229.

[30] du Plessis, J. N., Prinsloo, I. M. \& Groenewald, H. J. 2013. Results from implementing a remote diagnostic and maintenance solution on energy management systems. 2013 International Conference on Industrial and Commercial Use of Energy (ICUE), pp. 35-40.

[31] Renner, A., Williams, R., Harmon, B., Ganapathy, S., Abhyankar, K., West, J., Weiner, N., Weinle, N., McCartney, M. \& Boswell, L. 2014. RIPPLE: Scalable medical telemetry system for supporting combat rescue. NAECON 2014 - IEEE National Aerospace and Electronics Conference, pp. 228-232.

[32] Wannenburg, J. \& Malekian, R. 2015. Body Sensor Network for Mobile Health Monitoring, a Diagnosis and Anticipating System. IEEE Sensors Journal, 15(12), pp. 6839-6852.

[33] Civerchia, F., Bocchino, S., Salvadori, C., Rossi, E., Maggiani, L. \& Petracca, M. 2017. Industrial Internet of Things monitoring solution for advanced predictive maintenance applications. Journal of Industrial Information Integration, 7, pp. 4-12.

[34] Gungor, V. C. \& Hancke, G. P. 2009. Industrial Wireless Sensor Networks: Challenges, Design Principles, and Technical Approaches. IEEE Transactions on Industrial Electronics, 56(10), pp. 4258-4265.

[35] Gisbert, J. R., Palau, C., Uriarte, M., Prieto, G., Palazón, J. A., Esteve, M., López, O., Correas, J., Lucas-Estan, M. C., Giménez, P., Moyano, A., Collantes, L., Gozálvez, J., Molina, B., Lázaro, 0 \& González, A. 2014. Integrated system for control and monitoring industrial wireless networks for labor risk prevention. Journal of Network and Computer Applications, 39(1), pp. 233-252.

[36] Vermesan, O., Friess, P., Guillemin, P., Gusmeroli, S., Sundmaeker, H., Bassi, A., Jubert, I. S., Mazura, M., Harrison, M., Eisenhauer, M. \& Doody, P. 2011. Internet of Things Strategic Research Roadmap. Internet of Things - Global Technological and Societal Trends, pp. 9-52.

[37] du Plessis, J. N., Prinsloo, J. \& Vosloo, J. C. 2016. Reducing the Communication Costs of a Remote Monitoring and Maintenance System for an Energy Services Company (ESCo). SAlIE27 Proceedings, pp. 26131-2613-10.

[38] Wenwei, L., Dafang, Z., Jinmin, Y. \& Gaogang, X. 2007. On evaluating the differences of TCP and ICMP in network measurement. Computer Communications, 30(2), pp. 428-439.

[39] du Plessis, J. N., Pelzer, R. \& Kleingeld, M. 2012. An automated diagnostic system to streamline DSM project maintenance. 2012 International Conference on the Industrial and Commercial Use of Energy (ICUE), pp. 7-10.

[40] van Jaarsveld, S., du Plessis, J. N. \& Pelzer, R. 2015. A control system for the efficient operation of Bulk Air Coolers on a mine. 2015 International Conference on the Industrial and Commercial Use of Energy (ICUE), pp. 133-137.

[41] du Plessis, J. N., Pelzer, R. \& Vosloo, J. C. 2015. Sustaining the performance of diverse energy management systems through reactive maintenance. 2015 International Conference on the Industrial and Commercial Use of Energy (ICUE), pp. 44-49.

[42] Liebenberg, J. P. 2016. Developing a generic data translation platform. Master's thesis. Potchefstroom: NWU.

[43] Goosen, P. 2013. Efficient monitoring of mine compressed air savings. Master's thesis. Potchefstroom: NWU. 